\title{
Different wear in two highly cross-linked polyethylene liners in THA: wear analysis with EBRA
}

\author{
D. Dammerer ${ }^{1} \cdot$ A. Keiler ${ }^{1}$ (I) D. Putzer ${ }^{2} \cdot$ F. Lenze $^{3} \cdot$ M. Liebensteiner $^{1} \cdot$ M. Thaler $^{1}$
}

Received: 25 June 2020 / Accepted: 8 February 2021 / Published online: 4 March 2021

(c) The Author(s) 2021

\begin{abstract}
Introduction The purpose of this study was (1) to compare early wear rates in bedding-in periods of two highly cross-linked polyethylene liners frequently used in THA and (2) to evaluate risk factors indicating a possible higher wear rate.

Materials and methods 1120 patients who received a Crossfire or a Marathon highly cross-linked (HXLPE) ultra-highmolecular-weight polyethylene liner in primary THA at our Department between 2004 and 2018 were retrospectively reviewed. Patients with (1) only alumina heads on HXLPE acetabular bearings, (2) a minimum of four radiographs per patient for EBRA analysis, (3) no osteolysis around the acetabular cup and (4) no dislocations that occurred during the study period were included.

Results A total of 328 patients (female: 183; male: 145; Marathon: 179; Crossfire: 149) fulfilled the inclusion criteria. Mean follow-up was 24 (range 7-51) months. With 0.22 (SD 0.27) mm mean total wear for the Marathon was three times greater than for the Crossfire, namely 0.07 (SD 0.14 ) $\mathrm{mm}$. Mean cup migration during the investigated follow-up period was 0.7 (SD 0.8) $\mathrm{mm}$ for the Pinnacle and $0.5 \mathrm{~mm}$ (SD 0.7) for the Trident PSL cups.

Conclusion Initial early wear of highly cross-linked polyethylene in combination with alumina heads differs strongly between products. Long-term survivorship of these liners should be observed to determine whether early wear has an impact on aseptic loosening.
\end{abstract}

Level of evidence Level III (retrospective comparative study with prospective cohort).

Keywords Wear $\cdot$ EBRA $\cdot$ Cross-linked polyethylene $\cdot$ Cup migration

\section{Introduction}

Many long-term reports have described the success of total hip arthroplasty (THA) [1-5]. According to the current literature, cementless and cemented acetabular fixation show promising long-term results for up to 35 years [4-6]. Despite this improvement in fixation and the overall clinical success

A. Keiler

alexander.keiler@i-med.ac.at

1 Department of Orthopaedics and Traumatology, Medical University of Innsbruck, Anichstrasse 35, 6020 Innsbruck, Austria

2 Department of Orthopaedics and Traumatology, Experimental Orthopaedics, Medical University of Innsbruck, Sonnenburgstrasse 16, 6020 Innsbruck, Austria

3 Department of Orthopaedics and Sports Orthopaedics, Klinikum Rechts Der Isar, Technical University of Munich, Ismaninger Strasse 22, 81675 Munich, Germany of THA, there continues to be concern regarding durability of the bearing surface in terms of wear, osteolysis and loosening [1-5]. Osteolysis secondary to polyethylene (PE) wear has been described as one of the primary reasons for late revision of THAs [7]. Thus, PE wear remains a common reason for revision surgery following THA, and different arthroplasty registers show that changing a PE liner because of wear becomes necessary in approximately 10-20\% [8-12].

To reduce wear and improve the longevity of THA, highly cross-linked polyethylene liners were introduced for clinical use in 1998 and emerged as an alternative bearing [13]. In vitro studies suggested that conventional polyethylene can be highly cross-linked during the manufacturing process to provide a three-dimensional structure that is intrinsically resistant to wear [14-16]. During the first six months of clinical use a so-called creep deformation of the PE is mentioned rather than a wearing away of material [17]. According to the literature, in midterm studies of the highly cross-linked polyethylenes (with mean follow-up durations 
of approximately 5 years) investigators typically excluded the penetration data from the early bedding-in period (i.e., when creep is substantial) to obtain a more accurate measure of the actual steady-state wear rates [7]. Although during the first few years of clinical use the apparent wear rate of the highly cross-linked polyethylenes has been lower than that of traditional polyethylenes, total penetration during the first one to two years of use tends to be comparable for the two types of polyethylene, even if one wears substantially less than the other [7].

According to the Australian Orthopaedic Association National Joint Replacement Registry and its 2019 Annual Report, with a total of 8450 implanted cups the Trident PSL was the cup most commonly used in primary THA in 2018, followed by 6333 Pinnacle acetabular cups, thus making it the second most frequently used cup in primary THA in Australia [18]. During the same time, a total of 33,386 Trident PSL cups and 150,407 Pinnacle acetabular cups were implanted in THA in England, Wales, Northern Ireland and the Isle of Man. Thus, the Pinnacle was the most commonly used hip cup in England, Wales, Northern Ireland and the Isle of Man and the Trident was the second most widely used brand in 2018 [19]. In Germany, 1875 Trident and 17,878 Pinnacle cups were implanted in 2018 [20].

Overall, at 18 years the cumulative percent revision of total conventional hip replacement with XLPE is $7.2 \%$; but to date there is no report about the two in our study investigated liners [18].

The purpose of this study was (1) to compare early wear rates in bending-in periods of two frequently used highly cross-linked polyethylene liners in THA and (2) to evaluate risk factors indicating a possible higher wear rate.

\section{Materials and methods}

The study was approved by the local ethics committee. Written informed consent was obtained from all subjects before participation. All methods and measurements were carried out in accordance with relevant guidelines and regulations.

All consecutive patients who received a Crossfire (Stryker Orthopaedics, Mahwah, NJ, USA) or a Marathon (DePuy Synthes, Warsaw, IN, USA) highly cross-linked (HXLPE) ultra-high-molecular-weight polyethylene (UHMWPE) liner in a primary THA between 2004 and 2018 at our Department were retrospectively reviewed. During this time, a total of 1120 (Crossfire $n=636$; Marathon $n=484$ ) of the above-mentioned PE liners were implanted as acetabular bearing surface in primary THA. All Crossfire liners were used in Trident PSL cups (Stryker Orthopaedics, Mahwah, NJ, USA) and all Marathon liners were used in Pinnacle cups (DePuy Synthes, Warsaw, IN, USA). Figure 1 gives an example of a patient after bilateral THA that received

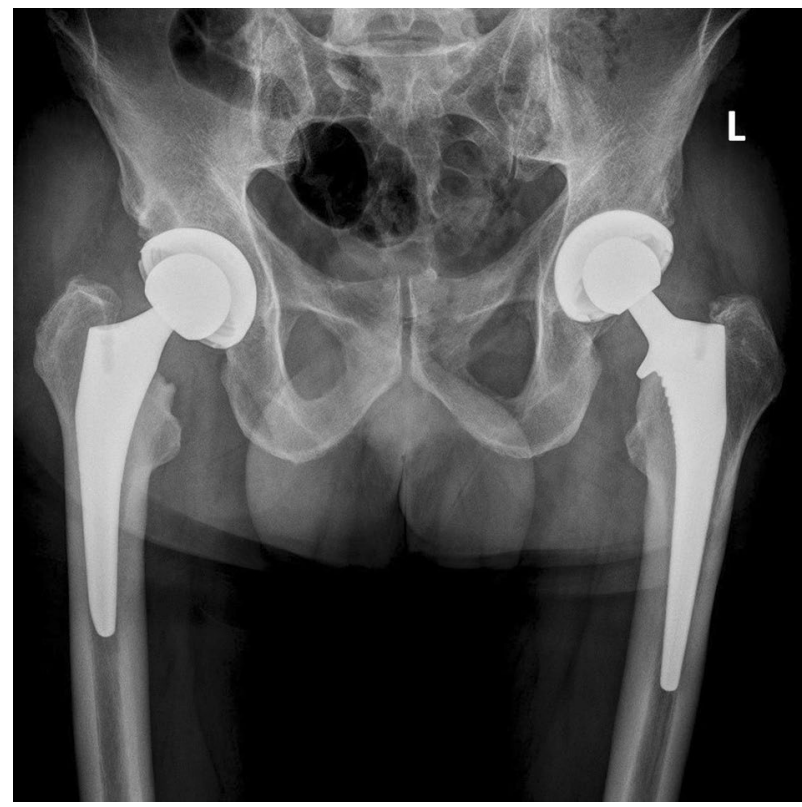

Fig. 1 Example of a patient after bilateral THA that received a Marathon liner in a Pinnacle cup (left hip) and a Crossfire liner in a Trident PSL cup (right hip)

both implants. The decision for one or the other type of cup was made by the surgeon himself, who preferred to use a particular cup type, and was not made by the patient. Thus, there was no selection bias.

Included were (1) only alumina heads on HXLPE acetabular bearings, (2) a minimum of four radiographs per patient for EBRA analysis, (3) no osteolyses were found around the acetabular cup and (4) no dislocation of the THA occurred during the investigated time period. Exclusion criteria were (1) revision of either the acetabular or (2) the femoral component, (3) a diagnosis of infection.

Prosthetic stability, PE wear and cup migration were assessed retrospectively with EBRA (German: Einzel-BildRöntgen-Analyse) [21] from plain $\mathrm{x}$ rays. EBRA is a wellestablished method that evaluates standard anterior-posterior radiographs without requiring additional means at exposure (e.g., ball markers). Simulating the spatial situation, it computes parameters of longitudinal and transverse migration of prosthetic cup, femoral head and wear. The migration of the femoral head, the acetabular cup and the wear in the horizontal and vertical directions can be studied. Total wear was calculated from the EBRA wear results in the horizontal and vertical directions by vectoral addition to make the results comparable with the results of other methods. Furthermore, total wear was calculated as the difference between migration of the head and cup in the horizontal and vertical directions. A comparability algorithm using a grid of transverse and longitudinal tangents of the pelvis contour divides serial radiographs into sets of comparable 
ones. Migration is measured only between comparable radiographs [21]. According to Callary et al., the variability in wear measurements observed with EBRA as compared to RSA is similar when using different acetabular reference segments [22].

In our Department, patients are followed with radiographs routinely before discharge, 6 weeks after surgery and 12 months postoperative. Additional radiographs are performed if the patient has any complaints with the THA. All radiographs were taken with the same technique (anterior-posterior (AP) radiographs; patient standing in upright position and full weight-bearing) following the EBRA protocol. For EBRA investigation, a minimum of four radiographs per patient and a minimum radiological follow-up of six months were required for this analysis. Wear and cup migration analysis was conducted with EBRA by one independent investigator, who was not involved in the surgeries or postoperative treatment of the patients.

The Marathon is a moderately cross-linked UHMWPE (ultra-high-molecular-weight polyethylene) liner that was clinically introduced in 1998 [23]. The liner is currently available for the Pinnacle and the Duraloc (DePuy Synthes, Warsaw, IN, USA) acetabular component system. In the Marathon process, an extruded rod bar stock is irradiated with a dose of $50 \mathrm{kGy}$ and then remelted at $150^{\circ}$ [24]. After remelting, the rods are then annealed at $120^{\circ}$ for $24 \mathrm{~h}$ [25]. Acetabular components are machined from the processed bar stock, enclosed in gas-permeable packaging, and then gas plasma-sterilized [26].

The Crossfire is an annealed highly cross-linked UHMWPE liner and was clinically introduced in 1998. The liner is currently available for the Trident acetabular cup design. In the Crossfire process, an extruded rod bar stock is irradiated with a nominal dose of $75 \mathrm{kGy}$ and then annealed at $130^{\circ}$ [27]. Acetabular components are machined from the bar stock, barrier-packaged in nitrogen (N2-VAC) and then gamma-sterilized with a nominal dose of $30 \mathrm{kGy}$. Consequently, components that have been through the Crossfire process have received a total dose of $105 \mathrm{kGy}[26,28]$.

\section{Statistical analysis}

Mean, median, range, and standard deviation were calculated for the different measurement parameters. Migration and wear rate were calculated as vectors of their corresponding components. For the analysis, Access and Excel (Microsoft Office Professional Plus 2010, Redmond, WA, USA) as well as Graph Pad Prism (Version 8.0, GraphPad Software, Inc., La Jolla, CA, USA) were used. The Kolmogorov-Smirnov test was performed to assess normal distribution of data. The independent samples Mann-Whitney U test was used to assess statistical significance in migration, wear rates, inclination and anteversion. A $p$ value of 0.05 was considered statistically significant.

\section{Results}

A total of 328 patients (female: 183; male: 145) fulfilled the inclusion criteria. For the Pinnacle study group a total of 179 patients (female: 100; male: 7) were recruited. Mean patient age at surgery was 69 (range 18-90) years and mean body mass index was 26.9 (range $18-50$ ) $\mathrm{kg} / \mathrm{m}^{2}$. Mean follow-up was 24 (range 7-51) months. For the Trident PSL group 149 patients (female: 83 , male: 66) were recruited. At the time of surgery, mean patient age was 65 (range 33-89) years and mean body mass index was 26.8 (range $15-39$ ) $\mathrm{kg} / \mathrm{m}^{2}$. Mean follow-up was four (range 2-9) years. Mean cut-to-suture time was 78 (range 36-209) min for the Pinnacle group and 72 (range 33-188) min for the Trident PSL group. In both study groups, a direct anterior approach [29] was used in supine position in almost all surgeries (Pinnacle: 99\%; Trident PSL: 99\%). Three patients (Pinnacle: 1\%; Trident PSL: $1 \%)$ were operated using a transgluteal approach [30]. The preoperative diagnosis was osteoarthritis in over $80 \%$ of both patient cohorts, followed by avascular necrosis of the femoral head (Pinnacle: 12\%; Trident PSL: 6\%) and femoral neck fracture (Pinnacle 2\%; Trident PSL: 1\%). In the Pinnacle group nine $(6 \%)$ patients were preoperatively diagnosed with dysplastic hip deformation. Details are shown in Table 1.

Table 1 Patient demographics (mean) of the study group. Range is given in brackets

\begin{tabular}{|c|c|c|}
\hline & Pinnacle (\%) & Trident PSL (\%) \\
\hline \multicolumn{3}{|l|}{ Number of patients } \\
\hline Female & $100(56 \%)$ & $83(56 \%)$ \\
\hline Male & $79(44 \%)$ & $66(44 \%)$ \\
\hline Total & 179 & 149 \\
\hline Mean age (years) & $67(18-90)$ & $64(32-89)$ \\
\hline BMI $\left(\mathrm{kg} / \mathrm{m}^{2}\right)$ & $26.8(18.3-50.8)$ & $26.8(15.2-39.4)$ \\
\hline Cut-to-suture time (min) & $78(36-209)$ & $72(33-188)$ \\
\hline \multicolumn{3}{|l|}{ Surgical approach } \\
\hline Direct anterior approach & $177(99 \%)$ & $146(99 \%)$ \\
\hline Transgluteal approach & $2(1 \%)$ & $1(1 \%)$ \\
\hline \multicolumn{3}{|l|}{ Surgical position } \\
\hline Supine & $179(100 \%)$ & $149(100 \%)$ \\
\hline \multicolumn{3}{|l|}{ Preoperative diagnosis } \\
\hline Osteoarthritis & $153(85 \%)$ & $130(87 \%)$ \\
\hline $\begin{array}{l}\text { Avascular necrosis of the } \\
\text { femoral head }\end{array}$ & $22(12 \%)$ & $9(6 \%)$ \\
\hline Fractures of femoral neck & $3(2 \%)$ & $1(1 \%)$ \\
\hline Dysplastic hip & $0(0 \%)$ & $9(6 \%)$ \\
\hline Pathologic FX & $1(1 \%)$ & $0(0 \%)$ \\
\hline
\end{tabular}


In all investigated cases alumina heads on HXLPE acetabular bearings were used. The most commonly used head size in both groups was $32 \mathrm{~mm}$ ( $n=163$ for the Pinnacle and $n=100$ for the Trident PSL study group). Other head sizes used were $28 \mathrm{~mm}(n=12$ for the Pinnacle and $n=20$ for the Trident PSL group) and $36 \mathrm{~mm}(n=2$ for the Pinnacle and $n=19$ for the Trident PSL group). Figure 2 shows the implanted cup sizes. For the Pinnacle group, cup size ranged from 46 to $66 \mathrm{~mm}$, for the Trident PSL group size ranged from 46 to $64 \mathrm{~mm}$.

According to the Kolmogorov-Smirnov test, migration, inclination, anteversion and wear rate were not normally distributed in the two groups $(p<0.05)$. Median cup migration during the investigated follow-up period was $0.5 \mathrm{~mm}(95 \%$ confidence interval; 0.6-0.8) for the Pinnacle and $0.2 \mathrm{~mm}$ (95\% confidence interval; 0.3-0.5) for the Trident PSL cups (Fig. 3). Cup migration was statistically significantly greater for the Pinnacle group than for the PSL group at 6 months $(p=0.023), 12$ months $(p=0.005)$ and 18 months $(p=0.038)$ follow-up. No statistically significant difference was found between the two groups after 24 months follow-up time $(p=0.089)$.

Cup inclination was $2^{\circ}$ greater for Trident PSL cups than for Pinnacle cups at six months follow-up $(p=0.003)$. No statistically significant difference was found between the two groups at 12 months $(p=0.069), 18$ months $(p=0.082)$ or 24 months $(p=0.081)$ follow-up time (Fig. 4, Table 2).

Pinnacle cups showed greater cup anteversion than did the PSL group (Fig. 4, Table 2). Pinnacle cups showed a statistically significantly greater anteversion of $2^{\circ}$ measured after six months $(p<0.001), 3^{\circ}$ greater anteversion measured

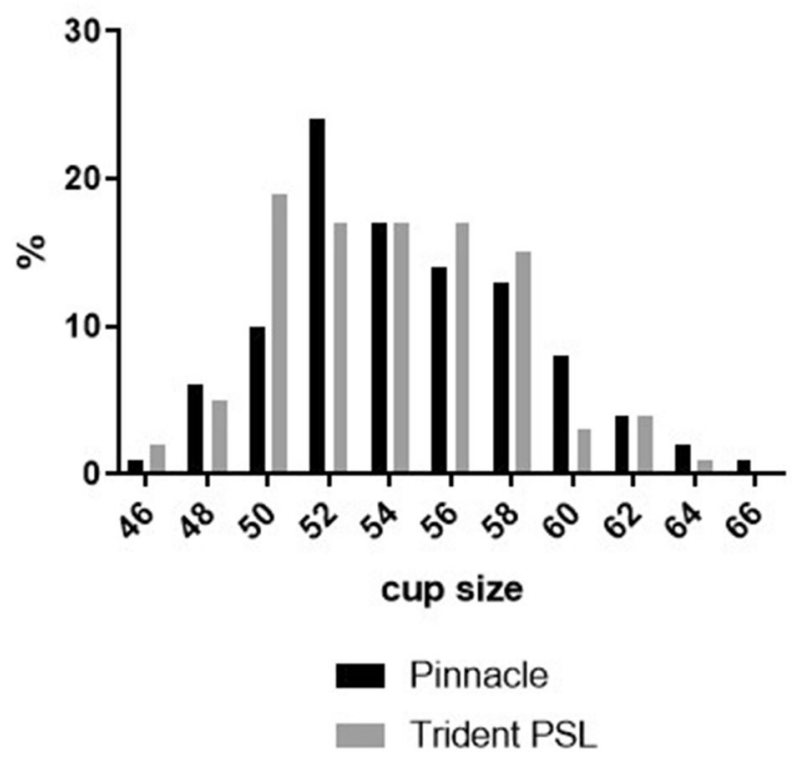

Fig. 2 Implanted cup sizes for the Pinnacle and the Trident PSL cohort

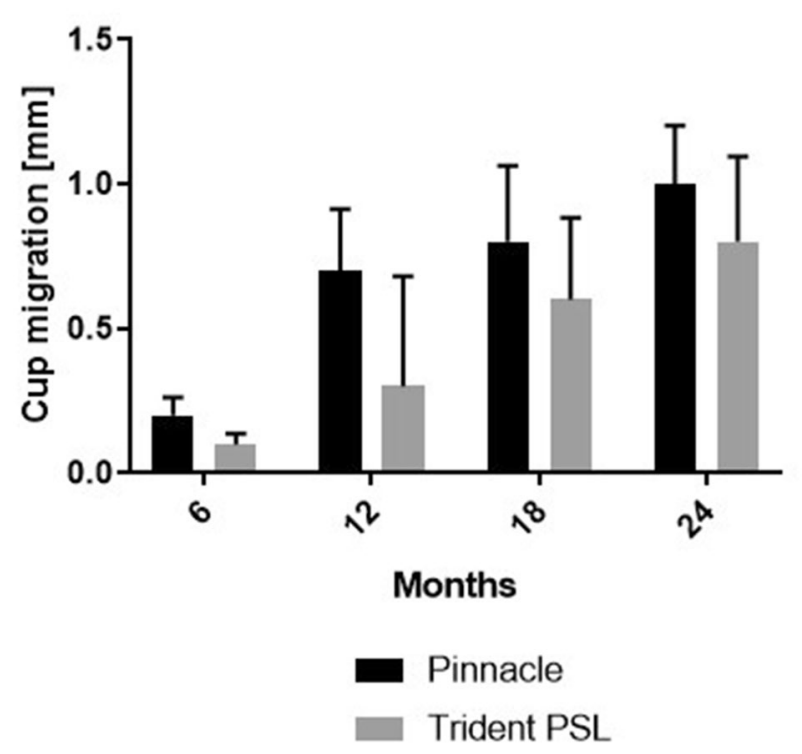

Fig. 3 Median cup migration for Trident PSL and Pinnacle. Bars indicate the $95 \%$ confidence interval

after 12 months $(p=0.012), 1^{\circ}$ greater anteversion measured after 18 months $(p=0.048)$ and $3^{\circ}$ greater anteversion ( $p=0.026)$ at the end of the follow-up period ( 24 months).

The wear rate showed a statistically highly significant difference between the two liners after $12(p<0.0001), 18$ $(p=0.018)$ and $24(p=0.002)$ months (Fig. 5, Table 2$)$. The Marathon liner showed a $0.4 \mathrm{~mm}$ higher wear rate after 12 months, a $0.8 \mathrm{~mm}$ higher wear rate after 18 months and a two-fold higher wear rate after 24 months than did the Crossfire. No statistical difference was found between the two liners after six months of our observed time period $(p=0.261)$ (Fig. 5, Table 2).

Median total wear was 0.11 (95\% interquartile interval; $0.15-0.21) \mathrm{mm}$ for the Marathon and 0.10 (95\% Interquartile interval; 0.10-0.13) $\mathrm{mm}$ for the Crossfire liner.

\section{Discussion}

The presented study investigated early wear in two very frequently used highly cross-linked UHMWPE acetabular liners in primary THA. The most important findings of the study were that the Marathon liner had a significantly higher wear rate than did the Crossfire and that the Pinnacle cup showed a higher migration rate than did the Trident PSL cup in the first two years postoperative. Additionally, to the best of our knowledge, this study presents the largest patient cohort to date, with more than 100 participants in each study group.

Previously published studies investigating the bearing surface in primary THA showed that wear and cup migration 

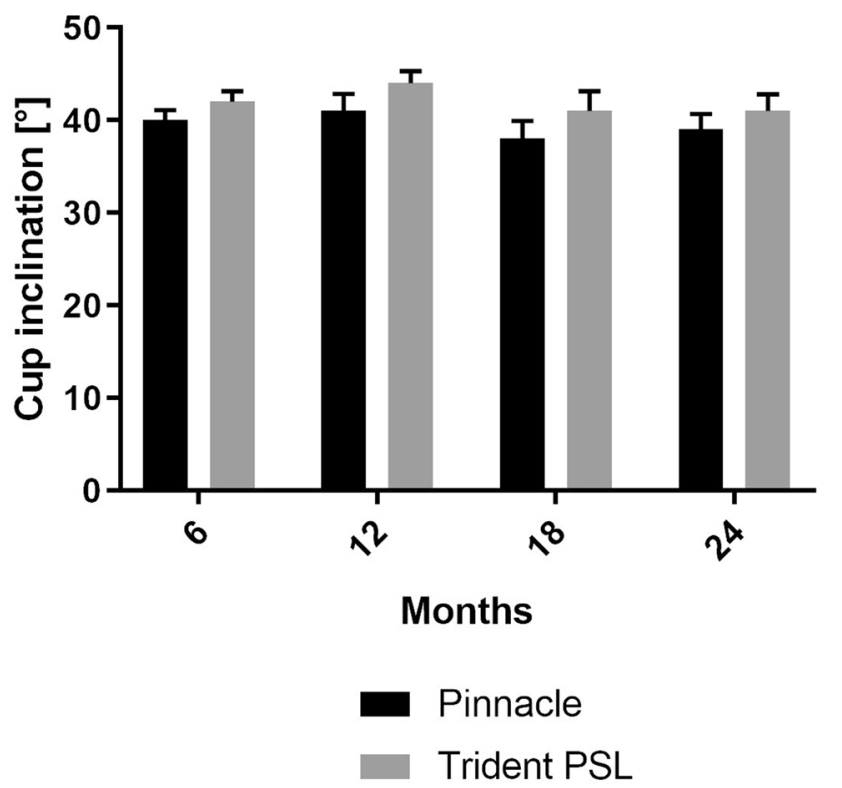
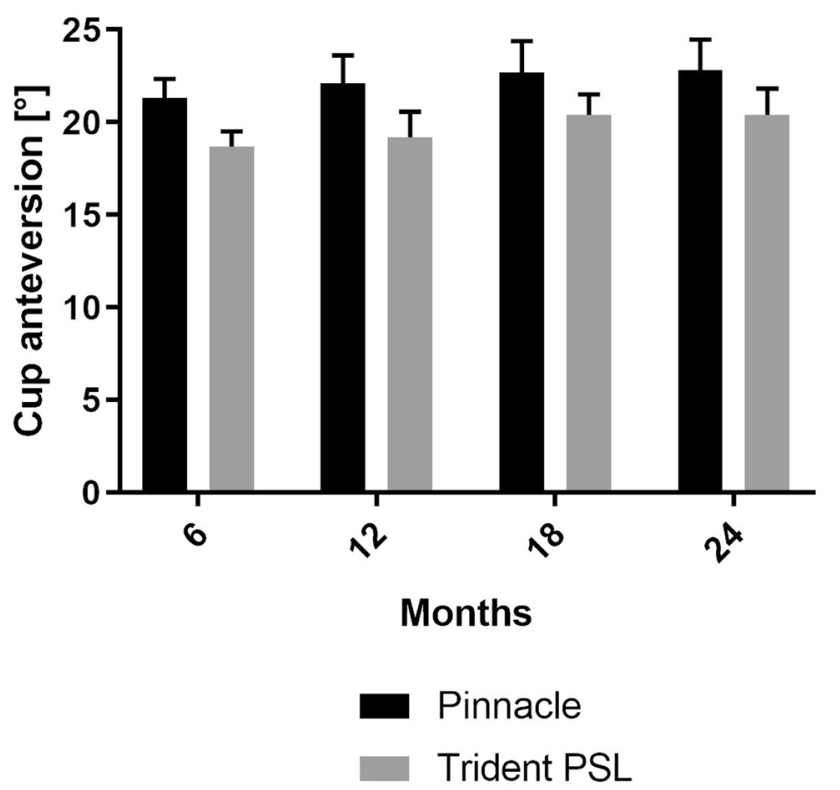

Fig. 4 Median cup inclination and anteversion (bars indicate the 95\% interval) for the clinical follow-up period of two years for the two study groups under investigation. Bars indicate the 95\% confidence interval (Pinnacle and Trident PSL)

Table 2 Details on cup median migration, inclination, anteversion and wear rate

\begin{tabular}{llcccc}
\hline & Cup type & 6 months & 12 months & 18 months & 24 months \\
\hline Median inclination $\left(^{\circ}\right)$ & Trident PSL & $42(41-44)$ & $44(41-46)$ & $41(40-44)$ & $41(39-44)$ \\
& Pinnacle & $40(39-41)$ & $41(39-43)$ & $38(38-42)$ & $39(37-41)$ \\
Median anteversion $\left(^{\circ}\right)$ & Trident PSL & $19(18-20)$ & $19(18-20)$ & $21(19-21)$ & $20(19-22)$ \\
& Pinnacle & $21(20-22)$ & $22(21-24)$ & $22(21-24)$ & $23(21-24)$ \\
Median migration $(\mathrm{mm})$ & Trident PSL & $0.1(0.1-0.2)$ & $0.3(0.3-1.0)$ & $0.6(0.5-1.0)$ & $0.8(0.7-1.2)$ \\
& Pinnacle & $0.2(0.2-0.3)$ & $0.7(0.7-1.1)$ & $0.8(0.8-1.4)$ & $1.0(0.9-1.4)$ \\
Median wear $(\mathrm{mm})$ & Trident PSL (Crossfire) & $0.00(0.03-0.06)$ & $0.10(0.08-0.14)$ & $0.14(0.14-0.23)$ & $0.14(0.17-0.29)$ \\
& Pinnacle (Marathon) & $0.05(0.05-0.08)$ & $0.14(0.15-0.26)$ & $0.22(0.19-0.34)$ & $0.28(0.27-0.46)$ \\
\hline
\end{tabular}

$95 \%$ confidence interval is given in brackets. All values in degrees

in the first two years postoperative are good predictors of later THA failure [31, 32]. The literature reports long-term wear rates of $0.04 \pm 0.02 \mathrm{~mm} /$ year for highly cross-linked polyethylene liners versus wear rates of $0.08 \pm 0.03 \mathrm{~mm} /$ year for conventional polyethylene [33]. These initial findings are not only useful for describing the mechanical properties of different PE liners, but are also of special clinical interest as a significant correlation was demonstrated between wear and reduced revision due to aseptic loosening and osteolysis [31, 34]. In mid- and long-term studies of HXLPE, investigators typically excluded the penetration data from the early bedding-in period (e.g., when creep is substantial) [7, 17]. This was done to obtain a more accurate measure of the actual steady-state wear rates and to exclude the creep deformation of PE, which typically occurs in the first six months of clinical use [7, 17]. The literature shows that investigations of the yearly wear rate of Marathon and Crossfire liners revealed a mean wear rate for the Marathon ranging from 0.01 to $0.08( \pm 0.07$ to \pm 0.24$) \mathrm{mm} / \mathrm{year}$, which is similar to the yearly wear rate of the Crossfire, namely ranging from 0.01 to $0.12 \pm 0.05 \mathrm{~mm} /$ year [35-41]. Tables 3 and 4 give an overview of peer-reviewed studies involving Crossfire (Table 3) and Marathon (Table 4) liners.

Whereas reported data show similar wear rates for the Crossfire group, there is a discrepancy in the wear rates for the Marathon liner. In our study, we found a highly significant difference in mean wear rate of $0.20 \mathrm{~mm}$ (SD 0.21) for the Marathon in comparison to $0.09 \mathrm{~mm}$ (SD 0.13) for the Crossfire $(p<0.0002)$. Both liners are XLPE, but there are differences in production, as mentioned in the Material and Methods section. According to the Australian Orthopaedic Association National Joint Replacement Registry 


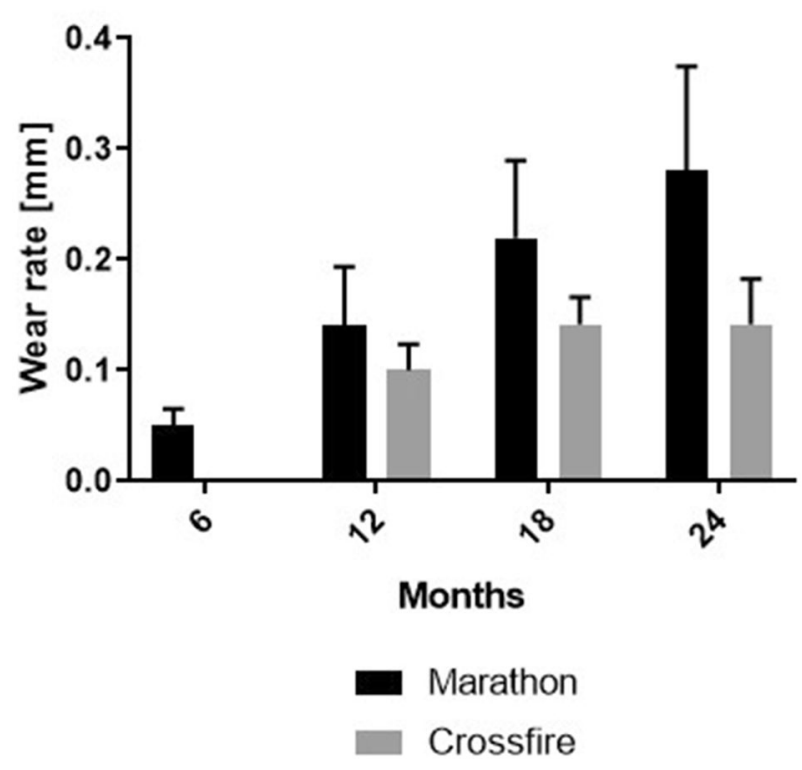

Fig. 5 Median wear rate of the two liners under investigation (Marathon-Pinnacle, Crossfire-Trident PSL) for the clinical follow-up period of two years. Bars indicate the $95 \%$ confidence interval
(AOANJRR) and its 2019 Annual Report, XLPE is classified as ultra-high-molecular-weight polyethylene that has been irradiated with high-dose ( $\geq 50 \mathrm{kGy}$ ) gamma or electron beam radiation [18]. The Marathon is irradiated with a dose of $50 \mathrm{kGy}$, whereas the Crossfire is irradiated with a nominal dose of $75 \mathrm{kGy}$ and then gamma-sterilized with a nominal dose of $30 \mathrm{kGy}$. Consequently, components that went through the Crossfire process received a total dose of $105 \mathrm{kGy}[24,27,28]$. The Crossfire received twice the dose of irradiation that the Marathon liner received. Therefore, the Marathon is stated to be a moderately cross-linked liner [23] compared to the highly cross-linked Crossfire. Our results suggest that the differences in the production of XLPE liners have a strong impact on their early wear rate.

It is well known that the size and material of the femoral head are further parameters influencing wear. Patients in both of our study groups received exclusively alumina ceramic heads. The majority of femoral head sizes implanted in our study was $32 \mathrm{~mm}$ and the current literature, for XLPE, shows the 32-mm head size to have the lowest rate of revision [18]. In mid- to long-term studies mainly $28 \mathrm{~mm}$ femoral heads were used. A recently published study by Gaudin et al. found no significant difference in either the mean linear or volumetric wear rates for $32 \mathrm{~mm}$ or $36 \mathrm{~mm}$ ceramic heads

WPE Biomaterials Handbook: Ultra High Molecular Weight Polyethylene in Total Joint Replacement and Medical Devices 3rd edition, Steven M. Kurtz and William Andrew, 2015 [47])
Table 3 Summary of peer-reviewed studies involving Crossfire linMolecular Weight Polyethylene in Total Joint Replacement and Medical Devices 2nd edition, Steven M. Kurtz, 2009 [46] and from UHM-

\begin{tabular}{|c|c|c|c|c|c|c|c|c|c|}
\hline Crossfire & $\begin{array}{l}\text { Martell } \\
2003[41]\end{array}$ & $\begin{array}{l}\text { Röhrl } 2005 \\
\text { [40] }\end{array}$ & $\begin{array}{l}\text { Krushell } \\
2005 \text { [39] }\end{array}$ & $\begin{array}{l}\text { D'Antonio } \\
2005 \text { [48] }\end{array}$ & $\begin{array}{l}\text { Röhrl } 2007 \\
\text { [38] }\end{array}$ & $\begin{array}{l}\text { Rajadhyak- } \\
\text { sha } 2009 \\
{[49]}\end{array}$ & $\begin{array}{l}\text { Capello } \\
2011[50]\end{array}$ & $\begin{array}{l}\text { Röhrl } 2012 \\
\text { [51] }\end{array}$ & $\begin{array}{l}\text { Epinette } 2014 \\
{[52]}\end{array}$ \\
\hline Study type & RCT & Pcoh & Hcoh & Hcoh & Pcoh & Hcoh & Hcoh & Pcoh & Hcoh \\
\hline Cup design & $\begin{array}{l}\text { Secur-Fit } \\
\text { HA PSL }\end{array}$ & Osteonics & $\begin{array}{l}\text { Microstruc- } \\
\text { tured PSL }\end{array}$ & $\begin{array}{l}\text { Microstruc- } \\
\text { tured PSL }\end{array}$ & Osteonics & $\begin{array}{l}\text { Microstruc- } \\
\text { tured PSL }\end{array}$ & $\begin{array}{c}\text { Secur-Fit } \\
\text { HA PSL }\end{array}$ & Osteonics & $\begin{array}{l}\text { Trident Arc } 2 \mathrm{f} \\
\text { threaded } \\
\text { cup }\end{array}$ \\
\hline Cup fixation & Uncemented & Cemented & Uncemented & Uncemented & Cemented & Uncemented & Uncemented & Cemented & Uncemented \\
\hline Head size & $28 \mathrm{~mm}$ & $28 \mathrm{~mm}$ & $28 \mathrm{~mm}$ & $28 \mathrm{~mm}$ & $28 \mathrm{~mm}$ & $28 \mathrm{~mm}$ & $28 \mathrm{~mm}$ & $28 \mathrm{~mm}$ & $\begin{array}{c}28 \mathrm{~mm} \text { or } \\
32 \mathrm{~mm}\end{array}$ \\
\hline $\begin{array}{l}\text { Head mate- } \\
\text { rial }\end{array}$ & $\begin{array}{l}\mathrm{CoCr} \\
\text { L-Fit }\end{array}$ & $\mathrm{CoCr}$ & $\begin{array}{l}\mathrm{CoCr} \\
\text { L-Fit }\end{array}$ & $\begin{array}{l}\mathrm{CoCr} \\
\text { L-Fit }\end{array}$ & $\mathrm{CoCr}$ & $\begin{array}{l}\mathrm{CoCr} \\
\text { L-Fit }\end{array}$ & $\mathrm{CoCr}$ & $\mathrm{CoCr}$ & ceramic \\
\hline $\begin{array}{l}\text { N (Cross- } \\
\text { fire) }\end{array}$ & 24 & 10 & 40 & 56 & 10 & 27 & 42 & 8 & 228 \\
\hline $\begin{array}{l}\text { Mean } \\
\text { follow-up } \\
\text { in years }\end{array}$ & 2.3 & 3.0 & 4.0 & 4.9 & 6.0 & 5.9 & 8.6 & 10.0 & 10.5 \\
\hline $\begin{array}{l}\text { 2-D liner } \\
\text { pen- } \\
\text { etration } \\
(\mathrm{mm} / \mathrm{y})\end{array}$ & $0.12 \pm 0.05$ & 0.02 & $0.05 \pm 0.02$ & $0.06 \pm 0.02$ & 0.01 & $0.05 \pm 0.04$ & $0.03 \pm 0.01$ & 0.02 & $0.02 \pm 0.01$ \\
\hline
\end{tabular}

Hcoh retrospective cohort study (Level III), Pcoh prospective cohort study, RCT randomized controlled trial (Level I), L-Fit low friction ion treatment; 2-D linear wear is listed for the longest follow-up period and includes the initial bedding-in period 
Table 4 Summary of peer-reviewed studies involving Marathon liners (adopted from UHMWPE Biomaterials Handbook: Ultra High Molecular Weight Polyethylene in Total Joint Replacement and Medical Devices 2nd edition, Steven M. Kurtz, 2009 [46] and from UHM-

\begin{tabular}{|c|c|c|c|c|c|c|c|}
\hline Marathon & $\begin{array}{l}\text { Hopper } 2003 \\
{[35]}\end{array}$ & Heisel 2004 [36] & $\begin{array}{l}\text { Heisel } 2005 \\
{[53]}\end{array}$ & Engh 2006 [37] & Bitsch 2008 [43] & Engh 2012 [54] & Bedard 2014 [1] \\
\hline Study type & Pcoh & Pcoh & Pcoh & RCT & Hcoh & RCT & Hcoh \\
\hline Cup design & Duraloc 100 & $\begin{array}{l}\text { Duraloc or Pin- } \\
\text { nacle }\end{array}$ & Duraloc & Duraloc 100 & $\begin{array}{l}\text { Duraloc or Pin- } \\
\text { nacle }\end{array}$ & Duraloc 100 & Pinnacle \\
\hline Cup fixation & Uncemented & Uncemented & Uncemented & Uncemented & Uncemented & Uncemented & Uncemented \\
\hline Head size & $28 \mathrm{~mm}$ & 28 or $32 \mathrm{~mm}$ & $28 \mathrm{~mm}$ & $28 \mathrm{~mm}$ & 28 or $32 \mathrm{~mm}$ & $28 \mathrm{~mm}$ & 28 or $32 \mathrm{~mm}$ \\
\hline Head material & $\mathrm{CoCr}$ & CoCr or ceramic & $\mathrm{CoCr}$ & $\mathrm{CoCr}$ & $\mathrm{CoCr}$ or ceramic & $\mathrm{CoCr}$ & $\mathrm{CoCr}$ \\
\hline N (Marathon) & 48 & 34 & 3 & 116 & 32 & 116 & 106 \\
\hline $\begin{array}{l}\text { Mean follow-up } \\
\text { in years }\end{array}$ & 2.9 & 2.8 & 3.2 & 5.7 & 5.8 & 10.6 & 8.9 \\
\hline $\begin{array}{l}\text { 2-D liner } \\
\text { penetration } \\
(\mathrm{mm} / \mathrm{y})\end{array}$ & $0.08 \pm 0.24$ & $0.02 \pm 0.1$ & $0.06 \pm 0.02$ & $0.01 \pm 0.07$ & $0.03 \pm 0.04$ & $0.04 \pm 0.06$ & $0.05 \pm 0.16$ \\
\hline
\end{tabular}

Hcoh retrospective cohort study (Level III), Pcoh prospective cohort study, RCT randomized controlled trial (Level I), L-Fit low friction ion treatment; 2-D linear wear is listed for the longest follow-up period and includes the initial bedding-in period

and highly cross-linked polyethylene [42]. This is also well in line with the 2019 Annual Report of the AOANJRR [18].

In clinical practice, increased liner wear rate does not only go along with an increased risk of osteolysis, loosening and revision rate [7]. There is a high rate of THA dislocation and a high rate of cup revision after liner exchange, as could be described in a recent publication by Dammerer et al. [55]. This means that every sixth patient with isolated liner exchange can expect to experience dislocation due to wear [55]. Therefore, we assume that our findings are not only statistically significant, but clinically relevant.

This study has several limitations including the retrospective methodology. Secondly, the follow-up period is short, which is certainly the study's most important limitation. Although there are some studies with a longer follow-up period, in most cases the number of patients included is much smaller than in our study. Moreover, to our knowledge, no other study describing the wear rates of Marathon and Crossfire liners has a sample size comparable to that of our study. Third, we used EBRA to measure cup migration and the wear rate of the PE liners. The radiographic assessment of small amounts of wear by means of the method used in the study poses some limitations, which have been recognized but are not unique to our study [43-45]. Additionally, the method of radiographic assessment of the wear rate on two-dimensional plane $\mathrm{x}$ ray pictures does not permit a volumetric wear rate to be calculated. We present only the two-dimensional linear penetration in millimeters. However, EBRA facilitates accurate and reliable analysis of wear and migration of components in hip arthroplasty [42]. Nevertheless, we used the same method to measure both components, the
WPE Biomaterials Handbook: Ultra High Molecular Weight Polyethylene in Total Joint Replacement and Medical Devices 3rd edition, Steven M. Kurtz and William Andrew, 2015 [47]) 
Consent to participate Written informed consent was obtained from all subjects before participation.

Open Access This article is licensed under a Creative Commons Attribution 4.0 International License, which permits use, sharing, adaptation, distribution and reproduction in any medium or format, as long as you give appropriate credit to the original author(s) and the source, provide a link to the Creative Commons licence, and indicate if changes were made. The images or other third party material in this article are included in the article's Creative Commons licence, unless indicated otherwise in a credit line to the material. If material is not included in the article's Creative Commons licence and your intended use is not permitted by statutory regulation or exceeds the permitted use, you will need to obtain permission directly from the copyright holder. To view a copy of this licence, visit http://creativecommons.org/licenses/by/4.0/.

\section{References}

1. Bedard NA, Callaghan JJ, Stefl MD et al (2014) Fixation and wear with a contemporary acetabular component and cross-linked polyethylene at minimum 10-year follow-up. J Arthroplasty 29:19611969. https://doi.org/10.1016/j.arth.2014.05.008

2. Takenaga RK, Callaghan JJ, Bedard NA et al (2012) Cementless total hip arthroplasty in patients fifty years of age or younger: a minimum ten-year follow-up. J Bone Jt Surg Ser A 94:2153-2159. https://doi.org/10.2106/JBJS.L.00011

3. Callaghan JJ, Bracha P, Liu SS et al (2009) Survivorship of a Charnley total hip arthroplasty: a concise follow-up, at a minimum of thirty-five years, of previous reports. J Bone Jt Surg Ser A 91:2617-2621. https://doi.org/10.2106/JBJS.H.01201

4. Della Valle CJ, Mesko NW, Quigley L et al (2009) Primary total hip arthroplasty with a porous-coated acetabular component: a concise follow-up, at a minimum of twenty years, of previous reports. J Bone Jt Surg Ser A 91:1130-1135. https://doi. org/10.2106/JBJS.H.00168

5. Stefl MD, Callaghan JJ, Liu SS et al (2012) Primary cementless acetabular fixation at a minimum of twenty years of follow-up: a concise update of a previous report. J Bone Jt Surg Ser A 94:234 239. https://doi.org/10.2106/JBJS.K.00237

6. Johnston; JGCPGS, (2004) Cementless acetabular fixation at fifteen years: a comparison with the same surgeon's results following acetabular fixation with cement. J Bone Jt Surg 86:257-261

7. Jacobs CA, Christensen CP, Greenwald AS, McKellop H (2007) Clinical performance of highly cross-linked polyethylenes in total hip arthroplasty. J Bone Jt Surg Ser A 89A:2779-2786

8. Petis SM, Kubista B, Hartzler RU et al (2019) Polyethylene liner and femoral head exchange in total hip arthroplasty: factors associated with long-term success and failure. J Bone Jt Surg Am 101:421-428. https://doi.org/10.2106/JBJS.18.00522

9. Manley MT, Sutton K (2008) Bearings of the future for total hip arthroplasty. J Arthroplasty 23:47. https://doi.org/10.1016/j. arth.2008.06.008

10. Adelani MA, Mall NA, Nyazee H et al (2014) Revision total hip arthroplasty with retained acetabular component. J Bone Jt Surg Am 96:1015-1020. https://doi.org/10.2106/JBJS.L.01177

11. Oberaigner W, Leitner H, Harrasser L, Krismer M BM (2015) Prothesenregister Tirol. Bericht über die Operationsjahre 2011-2013 und Revisionsstatistik der Operationsjahre 2004-2012. Innsbruck

12. Grimberg A, Jansson V, Liebs T et al (2016) Endoprothesenregister Deutschland (EPRD) Jahresbericht 2015

13. Mu Z, Tian J, Wu T et al (2009) A systematic review of radiological outcomes of highly cross-linked polyethylene versus conventional polyethylene in total hip arthroplasty. Int Orthop 33:599-604. https://doi.org/10.1007/s00264-008-0716-7

14. Graeter JH, Nevins R (1998) Early osteolysis with Hylamer acetabular liners. J Arthroplasty 13:464-466. https://doi.org/10.1016/ S0883-5403(98)90016-X

15. Muratoglu OK, Bragdon CR, O'Connor DO et al (2001) A novel method of cross-linking ultra-high-molecular-weight polyethylene to improve wear, reduce oxidation, and retain mechanical properties: recipient of the 1999 HAP Paul award. J Arthroplasty 16:149-160. https://doi.org/10.1054/arth.2001.20540

16. Saikko V, Calonius O, Keränen J (2002) Wear of conventional and cross-linked ultra-high-molecular-weight polyethylene acetabular cups against polished and roughened $\mathrm{CoCr}$ femoral heads in a biaxial hip simulator. J Biomed Mater Res 63:848-853. https:// doi.org/10.1002/jbm.10471

17. Digas G, Kärrholm J, Thanner J et al (2004) The otto aufranc award: highly cross-linked polyethylene in total hip arthroplastyrandomized evaluation of penetration rate in cemented and uncemented sockets using radiostereometric analysis. Clinical orthopaedics and related research. Lippincott Williams and Wilkins, Philadelphia, pp 6-16

18. (2019) Australian Orthopaedic Association National Joint Replacement Registry 20th Annual Report 2019

19. (2019) National Joint Registry for England, Wales, Northern Ireland and the Isle of Man 16th Annual Report 2019

20. Grimberg A, Jansson V, Melsheimer O, Steinbrück A (2019) Endoprothesenregister Deutschland [EPRD]—Jahresbericht 2019

21. Krismer M, Bauer R, Tschupik J, Mayrhofer P (1995) EBRA: a method to measure migration of acetabular components. J Biomech 28:1225-1236. https://doi.org/10.1016/00219290(94)00177-6

22. Callary SA, Solomon LB, Holubowycz OT et al (2017) Accuracy of methods to measure femoral head penetration within metalbacked acetabular components. J Orthop Res 35:988-996. https ://doi.org/10.1002/jor.23356

23. Barkatali BM, Alexander DP, Gambhir AK et al (2018) Wear rate and medium-term survival of a cemented, moderately cross-linked polyethylene acetabular prosthesis. HIP Int 28:53-58. https://doi. org/10.5301/hipint.5000521

24. McKellop H, FW S, Salovey R (1998) Extremely low wear of gamma-crosslinked/remelted UHMW polyethylene acetabular cups. 44th Annu. Meet. Orthop. Res. Soc. March 16-19, 1998, New Orleans, LA

25. Greer K, King R, Chan F (2004) The effects of raw material, irradiation dose, and irradiation source on crosslinking of UHMWPE. J ASTM Int 1:11217. https://doi.org/10.1520/jai11217

26. Kurtz SM, Zagorski M (2016) 3-packaging and sterilization of UHMWPE. In: Third E (ed) Kurtz SMBT-UBH. William Andrew Publishing, Oxford, pp 21-32

27. Kurtz SM, Manley M, Wang A et al (2002) Comparison of the properties of annealed crosslinked (Crossfire ${ }^{\mathrm{TM}}$ ) and conventional polyethylene as hip bearing materials. Bull Hosp Jt Dis 61:17-26

28. Kurtz SM (2016) 2-from ethylene gas to UHMWPE component: the process of producing orthopedic implants. In: Third E (ed) Kurtz SMBT-UBH. William Andrew Publishing, Oxford, pp 7-20

29. Rachbauer F (2005) [Minimally invasive total hip arthroplasty via direct anterior approach]. Orthopade 34:1103-1104, 1106-1108, 1110. https://doi.org/https://doi.org/10.1007/s00132-005-0854-1

30. Bauer R, Kerschbaumer F, Poisel S, Oberthaler W (1979) The transgluteal approach to the hip joint. Arch Orthop Trauma Surg 95:47-49. https://doi.org/10.1007/BF00379169

31. Nunag P, Deakin AH, Oburu E, Sarungi M (2012) Two-year radiologic assessment of the trident peripheral self-locking cup using EBRA. HIP Int 22:511-515. https://doi.org/10.5301/ HIP 2012.9744 
32. Krismer M, Stöckl B, Fischer M et al (1996) Early migration predicts late aseptic failure of hip sockets. J Bone Jt Surg Ser B 78:422-426. https://doi.org/10.1302/0301-620X.78B3.0780422

33. Teeter MG, Yuan X, Somerville LE et al (2017) Thirteen-year wear rate comparison of highly crosslinked and conventional polyethylene in total hip arthroplasty: long-term follow-up of a prospective randomized controlled trial. Can J Surg 60:212-216. https://doi.org/10.1503/cjs.005216

34. Hopper RH, Ho H, Sritulanondha S et al (2018) Otto Aufranc Award: crosslinking reduces THA wear, osteolysis, and revision rates at 15-year followup compared with noncrosslinked polyethylene. Clinical orthopaedics and related research. Lippincott Williams and Wilkins, Philadelphia, pp 279-290

35. Hopper RH, Young AM, Orishimo KF, McAuley JP (2003) Correlation between early and late wear rates in total hip arthroplasty with application to the performance of marathon cross-linked polyethylene liners. Journal of Arthroplasty. Churchill Livingstone Inc., London, pp 60-67

36. Heisel C, Silva M, Dela Rosa MA, Schmalzried TP (2004) Shortterm in vivo wear of cross-linked polyethylene. J Bone Jt Surg Ser A 86:748-751. https://doi.org/10.2106/00004623-20040 4000-00012

37. Engh CA, Stepniewski AS, Ginn SD et al (2006) A randomized prospective evaluation of outcomes after total hip arthroplasty using cross-linked marathon and non-cross-linked enduron polyethylene liners. J Arthroplasty 21:17-25. https://doi.org/10.1016/j. arth.2006.05.002

38. Röhrl SM, Li MG, Nilsson KG, Nivbrant B (2007) Very low wear of non-remelted highly cross-linked polyethylene cups: an RSA study lasting up to 6 years. Acta Orthop 78:739-745. https://doi. org/10.1080/17453670710014509

39. Krushell RJ, Fingeroth RJ, Cushing MC (2005) Early femoral head penetration of a highly cross-linked polyethylene liner vs a conventional polyethylene liner: a case-controlled study. J Arthroplasty 20:73-76

40. Röhrl S, Nivbrant B, Mingguo L, Hewitt B (2005) In vivo wear and migration of highly cross-linked polyethylene cups: a radiostereometry analysis study. J Arthroplasty 20:409-413. https://doi. org/10.1016/j.arth.2004.09.040

41. Martell JM, Verner JJ, Incavo SJ (2003) Clinical performance of a highly cross-linked polyethylene at two years in total hip arthroplasty: a randomized prospective trial. Journal of Arthroplasty. Churchill Livingstone Inc., London, pp 55-59

42. Abrahams JM, Callary SA, Jang SW et al (2020) Accuracy of EBRA-cup measurements after reconstruction of severe acetabular defects at revision THR. J Orthop Res. https://doi.org/10.1002/ jor. 24623

43. Bitsch RG, Loidolt T, Heisel C et al (2008) Reduction of osteolysis with use of marathon cross-linked polyethylene. J Bone Jt Surg Am 90:1487-1491. https://doi.org/10.2106/JBJS.F.00991

44. Martell JM, Berdia S (1997) Determination of polyethylene wear in total hip replacements with use of digital radiographs. J Bone
Jt Surg Ser A 79:1635-1641. https://doi.org/10.2106/00004623199711000-00004

45. Parran KK, Bechtel CP, Moore RD et al (2018) Are radiographic and direct measures of acetabular polyethylene wear comparable? J Arthroplasty 33:2677-2683. https://doi.org/10.1016/j. arth.2018.03.047

46. Kurtz SM (2009) UHMWPE biomaterials handbook: ultra high molecular weight polyethylene in total joint replacement and medical devices, 2nd edn. Elsevier Science, Oxford

47. Kurtz SM (2015) UHMWPE biomaterials handbook ultra high molecular weight polyethylene in total joint replacement and medical devices, 3rd edn. Elsevier Science, Oxford

48. D'Antonio JA, Manley MT, Capello WN et al (2005) Five-year experience with Crossfire ${ }^{\circledR}$ highly cross-linked polyethylene. Clin Orthop Relat Res 441:143-150. https://doi.org/10.1097/00003 086-200512000-00024

49. Rajadhyaksha AD, Brotea C, Cheung Y et al (2009) Five-year comparative study of highly cross-linked (crossfire) and traditional polyethylene. J Arthroplasty 24:161-167. https://doi. org/10.1016/j.arth.2007.09.015

50. Capello WN, D’Antonio JA, Ramakrishnan R, Naughton M (2011) Continued improved wear with an annealed highly cross-linked polyethylene. Clin Orthop Relat Res 469:825-830. https://doi. org/10.1007/s11999-010-1556-5

51. Röhrl SM, Nivbrant B, Nilsson KG (2012) No adverse effects of submelt-annealed highly crosslinked polyethylene in cemented cups: an RSA study of 8 patients 10 years after surgery. Acta Orthop 83:148-152

52. Epinette JA, Manley MT (2014) No differences found in bearing related hip survivorship at 10-12 years follow-up between patients with ceramic on highly cross-linked polyethylene bearings compared to patients with ceramic on ceramic bearings. J Arthroplasty 29:1369-1372. https://doi.org/10.1016/j.arth.2014.02.025

53. Heisel C, Silva M, Schmalzried TP (2005) In vivo wear of bilateral total hip replacements: conventional versus crosslinked polyethylene. Arch Orthop Trauma Surg 125:555-557. https://doi. org/10.1007/s00402-005-0041-1

54. Engh CA, Hopper RH, Huynh C et al (2012) A prospective, randomized study of cross-linked and non-cross-linked polyethylene for total hip arthroplasty at 10-year follow-up. J Arthroplasty. https ://doi.org/10.1016/j.arth.2012.03.048

55. Dammerer D, Schneider F, Renkawitz T et al (2020) High risk of hip dislocation following polyethylene liner exchange in total hip arthroplasty-is cup revision necessary? Arch Orthop Trauma Surg 140:1837-1845. https://doi.org/10.1007/s00402-020-03603 $-3$

Publisher's Note Springer Nature remains neutral with regard to jurisdictional claims in published maps and institutional affiliations. 